\title{
Coordinated Interaction between Hippocampal Sharp-Wave Ripples and Anterior Cingulate Unit Activity
}

\author{
DDong V. Wang and $\mathbb{C S}^{-S a t o s h i}$ Ikemoto \\ Behavioral Neuroscience Branch, National Institute on Drug Abuse, National Institutes of Health, Baltimore, Maryland 21224
}

\begin{abstract}
Hippocampal-cortical interaction during sleep promotes transformation of memory for long-term storage in the cortex. In particular, hippocampal sharp-wave ripple-associated neural activation is important for this transformation during slow-wave sleep. The anterior cingulate cortex (ACC) has been shown to be crucial for expression and likely storage of long-term memory. However, little is known about how ACC activity is influenced by hippocampal ripple activity during sleep. We report here about coordinated interactions between hippocampal ripple activity and ACC neural firings. By recording from the ACC and hippocampal CA1 simultaneously in mice, we found that almost all ACC neurons showed increased activity before hippocampal ripple activity; moreover, a subpopulation (17\%) displayed a further activation immediately after ripple activity. This postripple activation of ACC neurons correlated positively with ripple amplitude, and the same neurons were excited upon electrical stimulation of the CA1. Interestingly, the preripple activation of ACC neurons was present during the sleep state, but not during the awake state. These results suggest intimate interactions between hippocampal sharp-wave ripples and ACC neurons in a state-dependent manner. Importantly, sharp-wave ripples and associated activation appear to regulate activity of a small population of ACC neurons, a process that may play a critical role in memory consolidation.
\end{abstract}

Key words: anterior cingulate cortex; CA1; hippocampus; memory consolidation; sharp-wave ripple; unit activity

Significance Statement

The hippocampus communicates with the cortex for memory transformation. Memories of previous experiences become less dependent on the hippocampus and increasingly dependent on cortical areas, such as the anterior cingulate cortex (ACC). However, little evidence is available to directly support this hippocampus-to-cortex information transduction hypothesis of memory consolidation. Here we show that a subpopulation of ACC neurons becomes active just after hippocampal ripple activity, and that electrical stimulation of the hippocampus excites the same ACC neurons. In addition, the majority of ACC neurons are activated just before ripple activity during the sleep state, but not during the awake state. These results provide evidence supporting the hypothesis of hippocampus-to-cortex information flow for memory consolidation as well as reciprocal interaction between the hippocampus and the cortex.

\section{Introduction}

Converging evidence suggests that hippocampal-cortical interaction during sleep plays an important role in memory consolidation, a process that gradually transforms newly acquired information into long-term memory (Eichenbaum, 2000; Diekelmann and Born, 2010; Wang and Morris, 2010; Maingret et al., 2016). Over time,

Received March 29, 2016; revised Aug. 29, 2016; accepted Aug. 30, 2016.

Author contributions: D.V.W. designed research; D.V.W. performed research; D.V.W. analyzed data; D.V.W. and S.I. wrote the paper.

This work was supported by the Intramural Research Program of National Institute on Drug Abuse, National Institutes of Health. We thank Aleksandr Talishinsky, Andrew J. Kesner, and Alan B. Saul for their helpful comments on the manuscript.

The authors declare no competing financial interests.

Correspondence should be sent to either Dong Wang or Satoshi lkemoto, National Institute on Drug Abuse, 251 Bayview Boulevard, Suite 200, Baltimore, MD 21224. E-mail: dong.wang2@nih.gov or Satoshi.Ikemoto@nih.gov. DOI:10.1523/JNEUROSCI.1042-16.2016

Copyright $\odot 2016$ the authors $\quad 0270-6474 / 16 / 3610663-10 \$ 15.00 / 0$ memories of previous experiences become less dependent on the hippocampus, and increasingly dependent on cortical regions, such as the anterior cingulate cortex (ACC; Bontempi et al., 1999; Frankland et al., 2004; Maviel et al., 2004; Restivo et al., 2009; Goshen et al., 2011). Such a memory transformation process requires the hippocampus to communicate with the cortex over an extended period of time (Squire, 1992; McClelland et al., 1995). However, little evidence has been found to support this hippocampus-to-cortex information transduction hypothesis of memory consolidation (Siapas and Wilson, 1998; Wierzynski et al., 2009; Nir et al., 2011; Maingret et al., 2016).

Hippocampal ripple oscillation, a sharp-wave-associated fast field oscillation $(100-300 \mathrm{~Hz})$ that occurs predominantly during sleep and awake immobility (Ylinen et al., 1995), plays an important role in memory consolidation (Girardeau et al., 2009; EgoStengel and Wilson, 2010; Jadhav et al., 2012; Wang et al., 2015). During ripple oscillations, $\sim 5-20 \%$ of hippocampal neurons 
fire within a short time window of few hundred milliseconds (Ylinen et al., 1995; Nádasdy et al., 1999). A number of studies have shown that ripple-coincident neural firing during sleep is reminiscent of neural activity patterns associated with previous experiences (Wilson and McNaughton, 1994; Skaggs and McNaughton, 1996; Nádasdy et al., 1999; Lee and Wilson, 2002; Davidson et al., 2009). For example, hippocampal place cells that fire sequentially during spatial exploration will fire in a similar sequence during subsequent sleep, in a temporally compressed manner (Skaggs and McNaughton, 1996; Lee and Wilson, 2002; Davidson et al., 2009). This ripple-associated hippocampal neural reactivation, also known as "memory replay," is thought to potentiate relevant synaptic connections in the cortex, thereby transforming hippocampus-dependent memories into cortexdependent memories (Buzsáki, 1998; Diekelmann and Born, 2010; Girardeau and Zugaro, 2011).

Of many cortical regions, the ACC stands out as a critical site for storage and expression of long-term episodic memory. This has been demonstrated with widely used behavioral paradigms, including contextual fear conditioning, novel-object recognition, and spatial memory tests (Bontempi et al., 1999; Frankland et al., 2004; Maviel et al., 2004; Restivo et al., 2009; Goshen et al., 2011; Weible et al., 2012). However, little is known about how the ACC receives information from the hippocampus for memory consolidation. The present study provides evidence of twoway communication between ACC and hippocampus that may be important for memory consolidation.

\section{Materials and Methods}

Mice. Eight male C57BL/6J mice (3-5 months old; Jackson Laboratories) were used. After surgery, they were singly housed in a plastic cage $(30 \times$ $20 \times 20 \mathrm{~cm}$; referred to as home cage) containing woodchips and cotton material and kept on a $12 \mathrm{~h}$ light/dark cycle (lights on at 10:00 A.M.) and had ad libitum access to food and water. All procedures were approved by the Animal Care and Use Committee of the Intramural Research Program, National Institute on Drug Abuse, and were in accordance with National Research Council's Guide for the Care and Use of Laboratory Animals.

Stereotaxic surgery. Mice were anesthetized with a ketamine/xylazine mixture ( 100/10 mg per kg, i.p.) and received two bundles of electrode implantation, one into the CA1 and the other into the ACC, both in the right hemisphere. The coordinates for the ACC were anteroposterior (AP) $0.8 \mathrm{~mm}$ anterior from bregma, mediolateral (ML) $0.4 \mathrm{~mm}$ lateral from midline, dorsoventral (DV) $1.2 \mathrm{~mm}$ ventral from brain surface; the coordinates for CA1 were AP $-2.3 \mathrm{~mm}$, ML $1.7 \mathrm{~mm}$, and DV $1.1 \mathrm{~mm}$. The electrode bundles were slowly lowered and secured on the skull with stainless steel screws and dental cement. The ACC bundle consisted of eight tetrodes and was coupled with a movable microdrive; the CA1 bundle consisted of four tetrodes coupled with another microdrive (Wang et al., 2015). Each tetrode consisted of four wires (90\% platinum and $10 \%$ iridium; $18 \mu \mathrm{m}$ diameter with an impedance of $\sim 1-2$ $\mathrm{M} \Omega$ for each wire; California Fine Wire). At least $3 \mathrm{~d}$ after surgery, electrodes were screened for neural activity. All the data analyzed were recorded $\geq 6 \mathrm{~d}$ after surgery.

Tetrode recording. Neural signals were preamplified, digitized, and recorded using a Neuralynx Digital Lynx acquisition system; the animals' behaviors were simultaneously recorded. Local field potentials (LFPs) were digitized at $2 \mathrm{kHz}$ and filtered at $1-500 \mathrm{~Hz}$ or $150-250 \mathrm{~Hz}$ (ripples), using ground as the reference. If no clear ripple activity was detected, the electrode array was lowered by $\sim 80 \mu \mathrm{m}$ daily until a clear ripple activity was detected (with the ripple amplitude reaching $\geq 6 \mathrm{SDs}$ ). Spikes were digitized at $32 \mathrm{kHz}$ and filtered at $600-6000 \mathrm{~Hz}$, using one recording electrode that lacked obvious spike signals as the reference. All mice received $\geq 1$ session of recording of the CA1 and ACC simultaneously $(2-4 \mathrm{~h})$, plus another session of ACC recording upon CA1 electrical stimulation (1-2 h). Three intensities of electrical stimulation-35, 50, and $100 \mu \mathrm{A}$, each lasting $0.1 \mathrm{~ms}$ - were delivered intermittently at variable intervals between 10 and $15 \mathrm{~s}$. The lowest intensity of stimulation (35 $\mu \mathrm{A})$ evoked little response in the hippocampus, and thus was excluded from the study's analyses. After completion of the above recording sessions, the ACC electrode bundle was lowered by $\sim 80 \mu \mathrm{m}$ to record a deeper site in the ACC. A total of 2-3 sites in the ventral portion of ACC were recorded from each mouse. Electrical stimulation of the CA1 was delivered through two tetrodes of the electrode assembly.

Data analyses. Analyses on electrophysiological data were based on the sample size of 250 ACC neurons and LFPs recorded from eight mice (74, $46,32,29,20,18,18$, and 13 ACC neurons from individual mice). Spikes were sorted in OfflineSorter (Plexon), and sorted spikes were processed and analyzed in NeuroExplorer (Nex Technologies) and Matlab (Mathworks). Low-frequency neurons of $\leq 0.2 \mathrm{~Hz}$ were excluded from analyses due to an insufficient number of spikes. Ripples were bandpass filtered at $150-250 \mathrm{~Hz}$ (Neuralynx) and analyzed further in Matlab. A ripple event was defined as waves with the highest peak amplitude exceeding 4 SDs, plus two additional peaks exceeding 2 SDs and occurring within $\pm 30 \mathrm{~ms}$ of the highest peak. Identified ripples were further divided into highamplitude (peak amplitude, $>8$ SDs plus two additional $>4$ SDs), middle-amplitude (between 6 and 8 SDs plus two additional $>3$ SDs), and low-amplitude (4-6 SDs) events. High-amplitude plus middleamplitude ripple events were used for the analyses, unless otherwise stated. ACC LFPs were bandpass filtered at $1-4 \mathrm{~Hz}$ (Matlab), and an "up" state was defined as the period when an amplitude of the filtered LFP was $>1$ SD above mean and lasted $\geq 50 \mathrm{~ms}$. The slow-wave sleep (SWS) stage was determined by the theta $(6-10 \mathrm{~Hz}) /$ delta $(1-4 \mathrm{~Hz})$ ratio $(<1)$ extracted from the power spectra of hippocampal CAl when mice stayed immobile in their home cage's "bed," the cardboard box filled with cotton fiber material (Wang et al., 2015), where they exclusively slept. The awake immobile stage was determined when the mice were consuming rodent chow or rice.

ACC type I and II neurons. Firing rate changes were determined by comparing the number of spikes in a $250 \mathrm{~ms}$ window (starting at $200 \mathrm{~ms}$ before ripple peak) against that in a baseline $250 \mathrm{~ms}$ window (starting at $1200 \mathrm{~ms}$ before ripple peak), using the Wilcoxon signed-rank test. A $P$ value $\leq 0.01$ was defined as statistically significant. Because $97 \%$ of ACC neurons showed significant firing changes (96\% showed activation and $1 \%$ showed suppression), all ACC neurons were included for the classification of type I and type II neurons. We then computed periripple event histograms (smoothed with a three-bin Gaussian filter; bin size, $2 \mathrm{~ms}$ ) for individual ACC neurons (see Fig. 2D). If the highest value among periripple event histograms of a neuron was found within $100 \mathrm{~ms}$ after ripple peak, it was defined as type I; otherwise it was defined as type II.

The probability of the activation of each type I neuron was calculated using the definition of postripple activation as firing rate (calculated between 0 and $100 \mathrm{~ms}$ after ripple peak) that exceeds 2 SDs above baseline. Moreover, the chance of coactivation of a neuron pair was defined by multiplying $P_{1}$ and $P_{2}$, where $P_{1}$ and $P_{2}$ were the postripple activation probabilities of the two neurons.

Histology. The final electrode position was marked by passing a $10 \mu \mathrm{A}$, $20 \mathrm{~s}$ current through two tetrodes. Mice were deeply anesthetized and intracardially perfused with PBS followed by $4 \%$ paraformaldehyde (PFA). Brains were then removed and postfixed in PFA for $\geq 24 \mathrm{~h}$. Brains were sliced on a vibratome ( $60 \mu \mathrm{m}$ coronal sections) and sections were mounted with Mowiol mounting medium.

\section{Results}

\section{ACC neurons display ripple-associated activation}

To investigate whether the hippocampus influences ACC neural activity, we implanted a bundle of eight tetrodes in the ACC and another four tetrodes in the hippocampal CA1 region of C57BL/6J mice (for tetrode placements, see Fig. 1). We recorded unit activity and LFPs from the ACC and LFPs from the CA1 simultaneously (Fig. 2A), while the mice were lying still in a cotton-filled cardboard box (Wang et al., 2015), a state that most likely corresponds to sleep (Fig. 2B). Hippocampal ripple events were identified, and timestamps of the ripple peaks were used as 
A

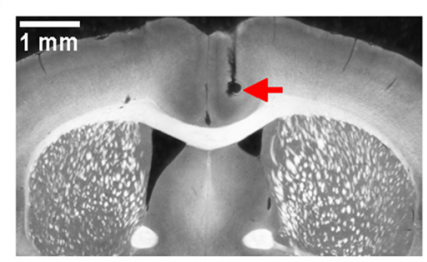

B

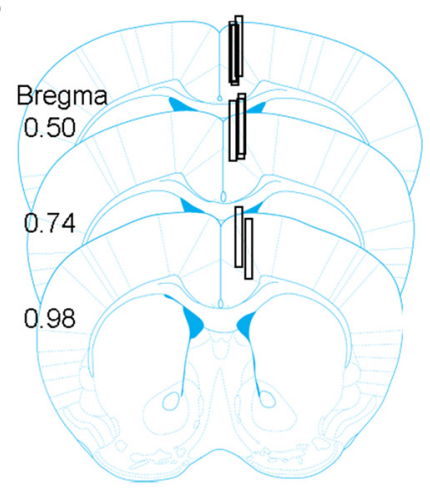

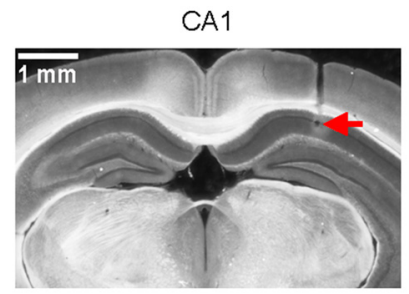

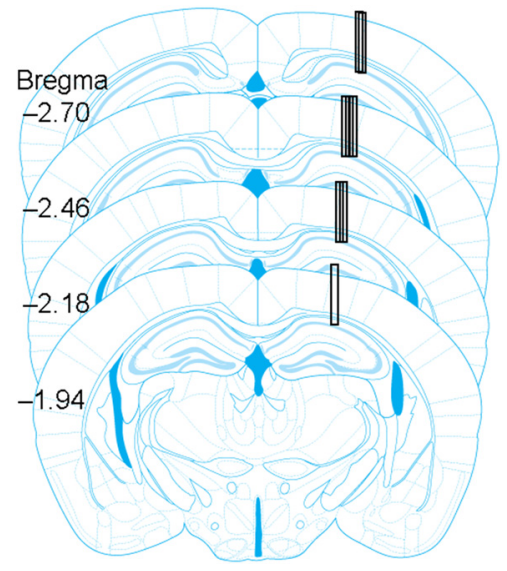

Figure 1. Recording sites. $A$, Two representative coronal sections showing the recording sites in the ACC (left) and hippocampal CA1 (right). The two sections are from the same mouse brain. $\boldsymbol{B}$, Individual recording sites (8 mice) are shown on schematic drawings of mouse brain (Franklin and Paxinos, 2007).

the reference to analyze their relationship to ACC activity (Fig. $2 C, D)$. ACC LFP displayed a depolarization starting $\sim 200 \mathrm{~ms}$ before ripple peak and a further depolarization immediately after (Fig. 2C, bottom). A total of 250 neurons were recorded from eight mice (Fig. 2E). Almost all of these ACC neurons displayed ripple-associated firing changes, and 97\% (242 of 250) of them reached statistical significance ( $p<0.01$; Wilcoxon signed-rank test). Based on the temporal relationship to ripple events, the ACC neurons were classified into two types: type I (17\%) and type II (83\%; Fig. 2F: neurons $1-43$ and 44-250, respectively). While both types of neurons displayed increased activity starting $\sim 200$ ms before ripple peak, type I neurons displayed a second greater activation immediately after ripple peak (Fig. $2 D, F$ ).

To determine whether ACC type I and type II neurons have differential firing properties, we performed autocorrelation analyses on individual ACC neurons (Fig. $3 A, B$ ). Our results show that the type I neurons have a higher probability of firing with short interspike intervals (i.e., burst or burst-like firing) than type II neurons (Fig. $3 \mathrm{~B}, \mathrm{C})$. Pooling all ACC neurons, the postripple firing change of ACC neurons is positively correlated with the amplitude of the autocorrelation histogram peak, and it is also negatively correlated with the latency of the autocorrelation histogram peak (Fig. 3D). These results suggest that ACC type I and type II neurons have different firing properties, and that type I neurons are more likely to exhibit burst or burst-like firings.

The observation that ACC type I neurons show increased activity immediately after ripple events led us to further investigate whether the activation level of type I neurons correlates with ripple amplitude. Specifically, ACC neural activity was analyzed in relation to ripple amplitudes classified into high, middle, and low levels (Fig. $4 A, B$ ). The postripple depolarization of ACC LFP was proportional to ripple amplitude $\left(p=1.7 \times 10^{-6}\right.$, one-way ANOVA; $n=8$; Fig. $4 A$, right). Moreover, peak firing rates of AAC type I neurons, which occurred $12 \mathrm{~ms}$ on average (ranging from 6 to $32 \mathrm{~ms}$ ) after ripple peaks, increased significantly as

ripple amplitudes increased $(p=4.0 \times$ $10^{-11}$, one-way ANOVA; $n=43$; Fig. $4 B$, left, $C$ ). The peak firing rates of ACC type II neurons occurred $86 \mathrm{~ms}$ on average before ripple peaks. Although type II neuron peak firing rate also increased as ripple amplitudes increased $\left(p=6.5 \times 10^{-11}\right.$, one-way ANOVA; $n=207$; Fig. $4 B$, right), the increases were much smaller than those of type I neurons (Fig. 4C). Similar to that of type II neurons, the preripple firing rate of type I neurons slightly increased as ripple amplitudes increased $\left(p=5.5 \times 10^{-6}\right.$, one-way ANOVA; Fig. $4 B$, left).

Although the analysis above suggests that greater amplitudes of ripple events predict greater postripple firing rates of type I neurons (Fig. 4C), we found that ACC type I neurons did not always increase their firing rates after ripple events. Individual type I neurons had a postripple activation probability of $23 \%$ on average (ranging from 7 to $47 \%$ ) following highamplitude and middle-amplitude ripple events (Fig. 4D). In addition, the probability of two type I neurons firing concurrently postripple was only slightly higher than chance ( 6.8 vs $5.4 \%, p=4.2 \times 10^{-9}$, paired $t$ test; Fig. $4 D$ ). Together, these results suggest that hippocampal ripple activity does not exert uniform effects over ACC neurons; the results are consistent with the notion that the hippocampus communicates with ACC type I neurons selectively in an informationdependent manner.

\section{ACC neurons are selectively activated by CA1 stimulation}

To determine whether hippocampal activity indeed influences ACC neural activity, we stimulated the hippocampal CA1 (through two tetrodes) while recording from the ACC. We first identified ACC type I and II neurons based on their relationship to ripple events (Fig. 5A), similar to that described above (Fig. 2). Single-pulse (lasting $0.1 \mathrm{~ms}$ ) electrical stimuli were delivered to the CA1 with variable intertrial intervals (between 10 and $15 \mathrm{~s}$ ) while continuously recording from the ACC. CA1 stimulation evoked a fast excitation of the majority of ACC type I neurons and the minority of type II neurons (Fig. 5B-D), confirming that ACC neurons were influenced by hippocampal activity. In summary, $\sim 62 \%$ of ACC type I neurons (21 of 34) were excited following CA1 stimulation, with firing peaking at $23 \mathrm{~ms}$ on average (ranging from 10 to $60 \mathrm{~ms}$ ) after the stimulation (Fig. $5 D, E$ ). On the other hand, $\sim 31 \%$ (50 of 161) of ACC type II neurons were excited following CA1 stimulation, with firing peaking at $28 \mathrm{~ms}$ on average (ranging from 5 to $55 \mathrm{~ms}$ ) after the stimulation (Fig. $5 D, E$ ). Both types of neurons also displayed a delayed suppression following CA1 stimulation (between $\sim 50$ and $200 \mathrm{~ms}$; Fig. 5E). Pooling all ACC neurons, we found that the poststimulation firing changes of ACC neurons are positively correlated with the postripple firing changes (Fig. $5 F$ ). These results suggest that hippocampal activity indeed influences ACC neural activity, especially that of type I neurons. 
A

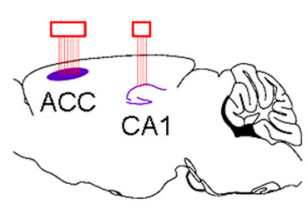

dual-site recording
B

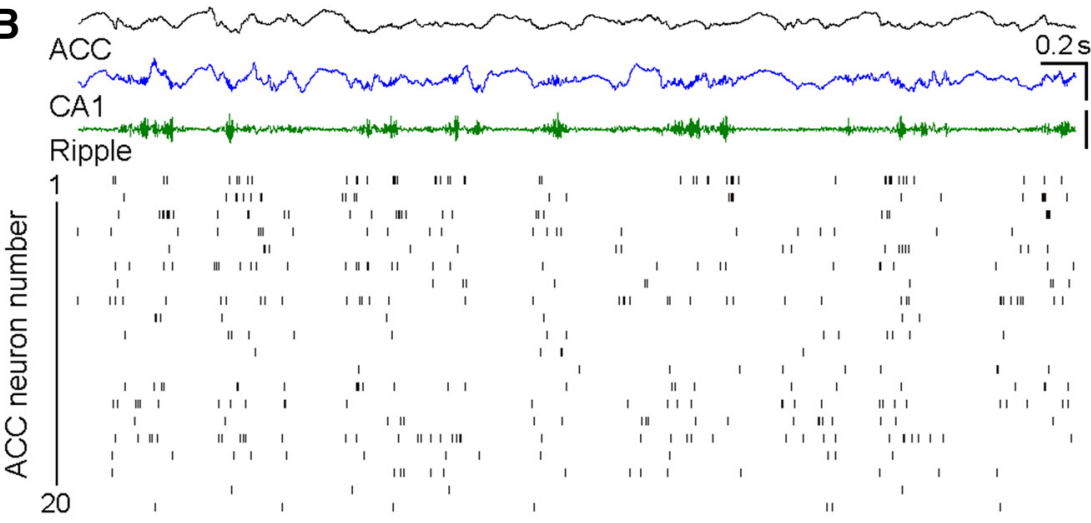

Type I

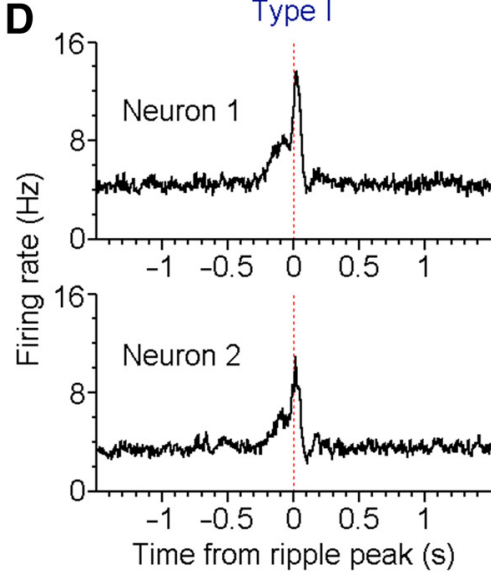

Type II

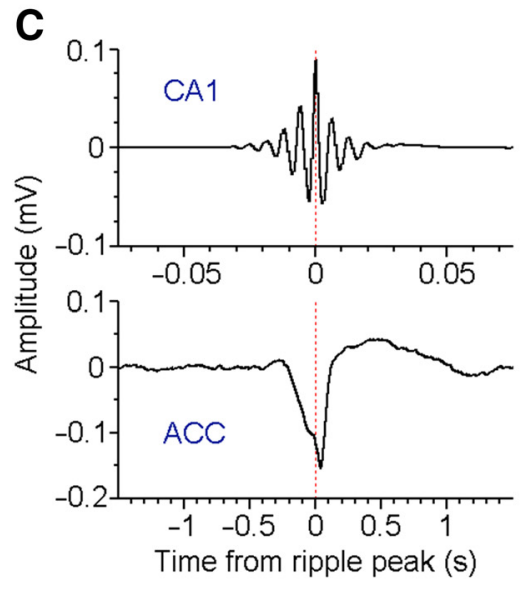

E

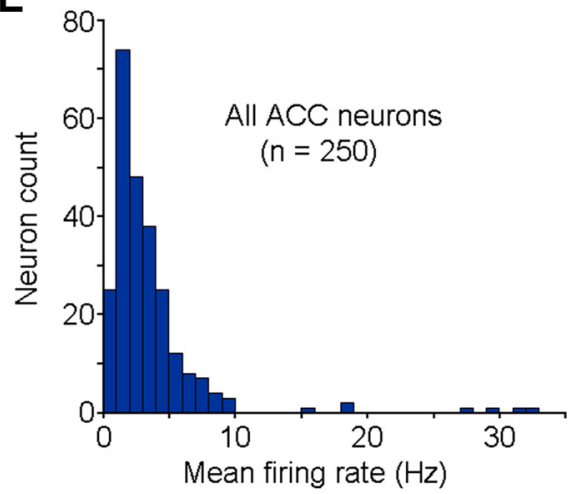

$\mathbf{F}$

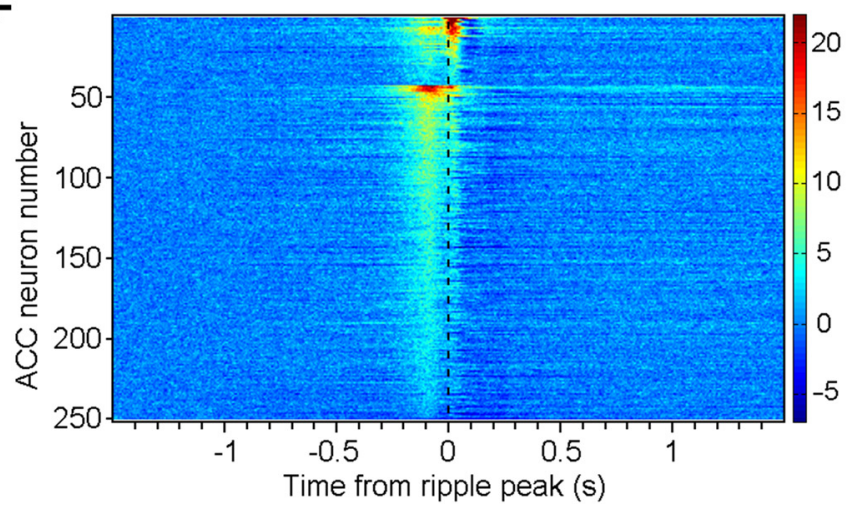

Figure 2. ACC neurons display hippocampal ripple-associated activation. $A$, Schematic drawing of dual-site recording in the ACC and hippocampal CA1. B, Representative LFPs (ACC and CA1), ripple ( $150-250 \mathrm{~Hz}$ filtered), and spikes of $20 \mathrm{ACC}$ neurons recorded simultaneously. Vertical scale bars: for ACC, $2 \mathrm{mV}$; for CA1, $0.3 \mathrm{mV}$. C, Mean of 4285 ripple events (top) and mean of ACC LFP (bottom) in relation to the ripple peak. $\boldsymbol{D}$, Activity of four ACC neurons ( $\boldsymbol{B}$, first 4 neurons) in relation to ripple peak ( $n=4285)$. $\boldsymbol{E}$, Basal firing rate distribution of all recorded ACC neurons $(n=250)$. $\boldsymbol{F}$, Summary of all ACC neurons in relation to ripple peak $(n=250)$. Neurons $1-43$ and $44-250$ are type I and type II neurons, respectively. Color bar represents $z$-scored firing frequency.

\section{Differential ripple-correlated ACC activity between awake and sleep}

While the above results on hippocampus-ACC correlation were obtained during SWS, increasing evidence suggests that rippleassociated neural activity differs between SWS and awake immobile states (Foster and Wilson, 2006; Carr et al., 2011; Pfeiffer and Foster, 2013; Remondes and Wilson, 2015). To determine whether the hippocampus and ACC communicate differentially between the two states, we compared hippocampus-ACC activities when the mice were sleeping (SWS) and feeding (awake immobile). We found that ACC type I neurons displayed rippleassociated activation in both states (Fig. 6A; neurons 1-22). Interestingly, ACC type I neurons largely lost their preripple ac- tivation in the awake immobile state (Fig. 6B, left). Similarly, type II neurons did not display preripple activation during the awake immobile state (Fig. $6 A$, neurons $23-118, B$, right). These results suggest that the preripple activation of ACC neurons is not necessary for the generation of hippocampal ripple activity, at least during the awake immobile state.

\section{Hippocampal ripples preferentially occur during ACC} up state

Cortical activity is known to alternate between up (depolarization) and "down" (hyperpolarization) states during SWS. ACC LFPs across the electrodes exhibited clearly such up-and-down transitions (Fig. 7A). To determine whether hippocampal ripples 
A

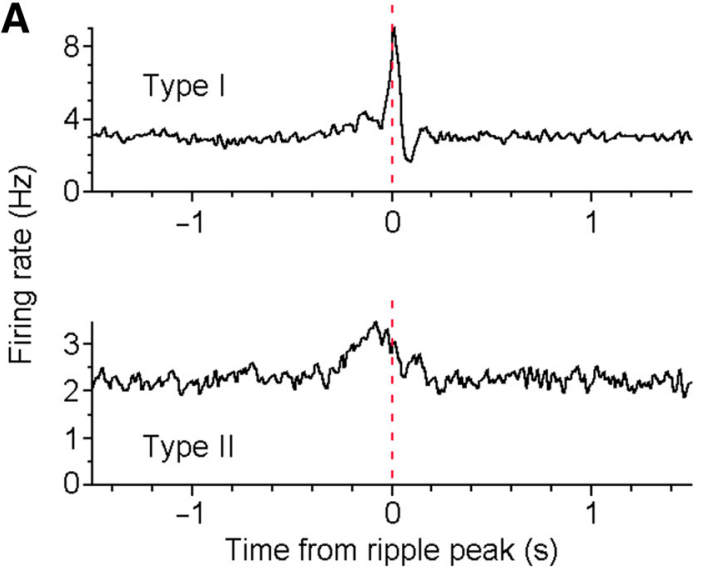

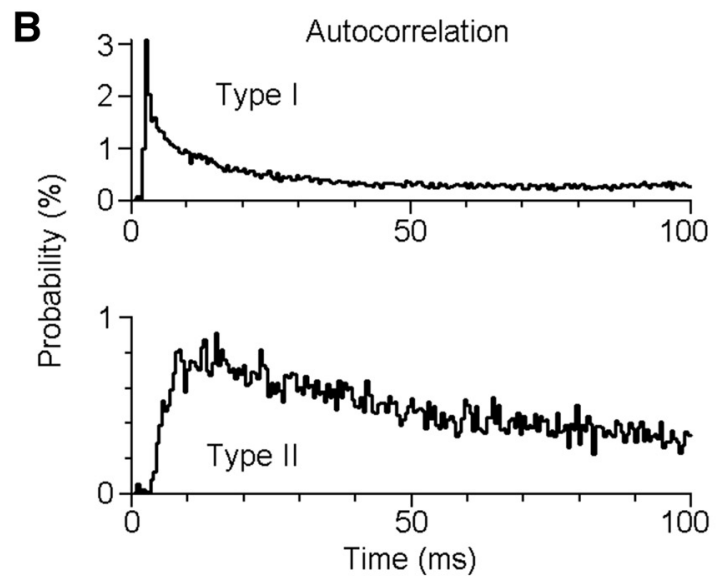

C

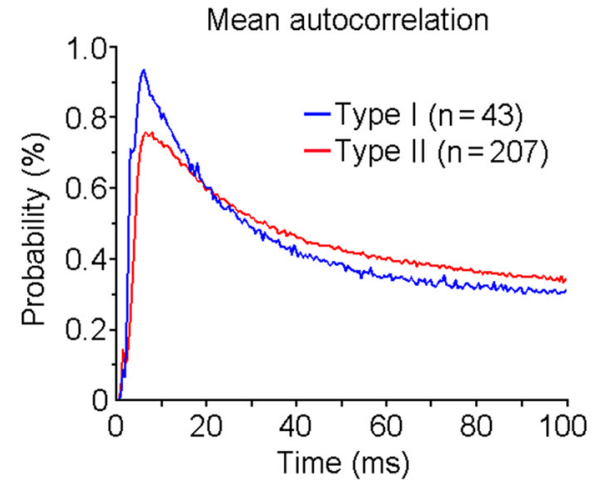

D

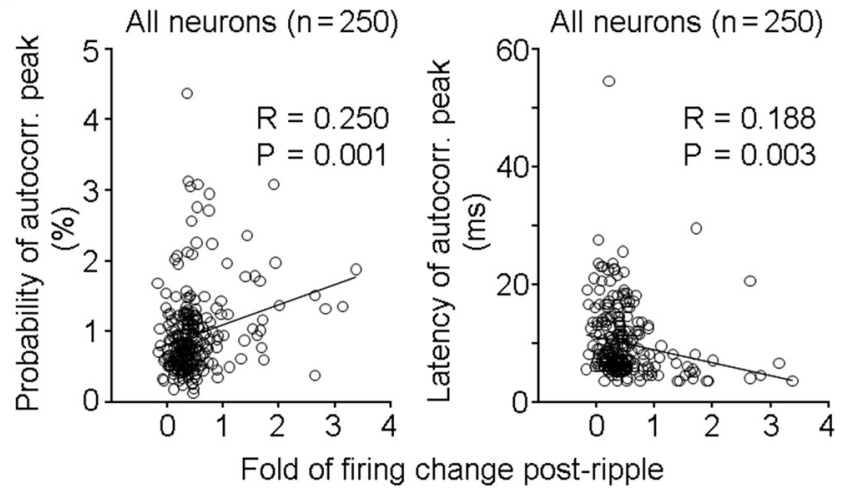

Figure 3. Differential firing patterns of ACC type I and type II neurons. $A$, Activity of two simultaneously recorded ACC neurons in relation to ripple peak. $B$, Autocorrelograms of the same two neurons (as shown in $A$ ). C, Mean autocorrelograms of ACC type I $(n=43)$ and type II $(n=207)$ neurons. $D$, Left, The postripple firing change of ACC neurons is positively correlated with the amplitude of the autocorrelogram peak. Right, The postripple firing change of ACC neurons is negatively correlated with the latency of the autocorrelogram peak. Fold firing change is defined as the maximum firing rate change (between 0 and $0.1 \mathrm{~s}$ postripple as shown in $A$ ) divided by baseline firing rate (between 1 and $1.5 \mathrm{~s}$ preripple). Each circle represents one ACC neuron.

correlated with ACC states, we identified individual ACC up and down states (Fig. $7 B, C$, left) and examined their relationship with ripple events (Fig. $7 B, C$, right). We found that hippocampal ripple activity increased during the up state and decreased during the down state (Fig. $7 \mathrm{~B}, \mathrm{C}$, right), indicating a coordinated ACChippocampus communication during SWS. Similarly, both ACC type I and type II neurons increased activity during the up state and decreased activity during the down state (Fig. 7D). This increased ACC activity appeared to slightly precede the increased hippocampal ripple activity, which is consistent with our previous analysis (Fig. 2F).

\section{Discussion}

The present study found that the majority of the ACC neurons exhibited a preripple activation. In addition, a subpopulation of these preactivated ACC neurons was selectively influenced by hippocampal ripple activity. These findings suggest that there is likely two-way communication between the ACC and hippocampus during sleep. While the ACC can be considered a posterior portion of the medial prefrontal cortex (mPFC), the ACC should be distinguished from typical mPFC at the level of the prelimbic cortex. Notably, the present study did not find clear spindle activity $(10-20 \mathrm{~Hz})$ in the ACC, although spindle activity has previously been reported in the mPFC (Siapas and Wilson, 1998; Maingret et al., 2016). We should also mention that the precise temporal relationships between hippocampal ripple activity and ACC unit activity might have been slightly different if the analysis had focused on the onsets of ripple and ACC unit activities, instead of ripple peak and firing rate peak of ACC units. However, due to the overlapping of preripple and postripple activation of the type I neurons, it would be difficult to calculate the onsets of their postripple activation.

\section{Hippocampus-to-cortex information flow during sleep}

A critical aspect of the hippocampal-cortical memory consolidation hypotheses is the direction of information flow (Buzsáki, 1998; Tononi et al., 2006; Mölle and Born, 2009). It has been widely hypothesized that the hippocampus transforms its temporally stored information into the cortex for long-term storage over an extended period of time (Buzsáki, 1998; Diekelmann and Born, 2010; Girardeau and Zugaro, 2011). Indeed, several studies have provided substantial evidence that hippocampal ripple or single-unit activity occurs just before the activation of cortical neurons (Wierzynski et al., 2009; Nir et al., 2011), and that hippocampal ripple and associated reactivation tend to occur before cortical memory reactivation (Ji and Wilson, 2007; Peyrache et al., 2009). We found that a subpopulation (type I) further increased their firing immediately after ripple activity during sleep. This postripple activation of type I neurons correlated positively with ripple amplitude. Moreover, the same neurons were activated upon electrical stimulation of hippocampal CA1. These results suggest that hippocampal ripple activity selectively affects a 

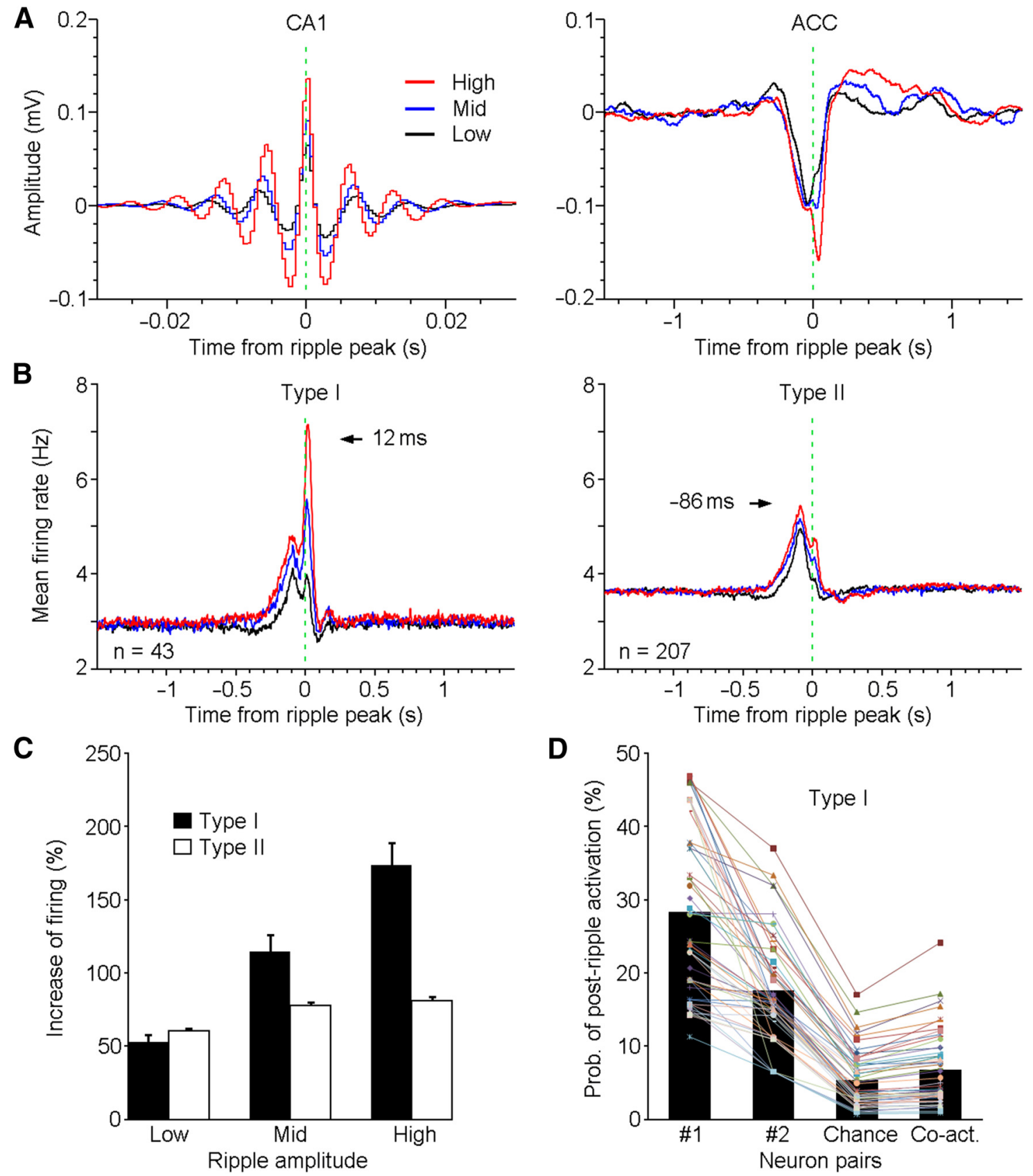

Figure 4. ACC neural activity correlates with hippocampal ripple amplitude. $\boldsymbol{A}$, Left, Representative means of high-amplitude (peak amplitude, $>8$ SDs; $n=2725)$, middle-amplitude $(6-8$ SDs; $n=1482$ ), and low-amplitude (4-6 SDs; $n=2582$ ) ripple events recorded in one session. Right, Means of ACC LFP in relation to the high-amplitude (red), middle-amplitude (blue), and low-amplitude (black) ripple events, respectively. $\boldsymbol{B}$, Mean firing rates of type I (left; $n=43$ ) and type II neurons (right; $n=207$ ) in relation to high-amplitude, middle-amplitude, and low-amplitude ripple events, respectively. Mean latencies between firing-rate peaks and ripple peaks of type I and II neurons are 12 and -86 ms on average, respectively. $C$, Peak firing rates of $A C C$ type I and II neurons significantly increased as ripple amplitude increased. Type I: $F_{(2,126)}=29.12, p=4.0^{-11} \times 10^{-11} ;$ type II: $F_{(2,618)}=24.39, p=6.5 \times 10^{-11}$; one-way ANOVA. $D$, Probability of postripple activation of type I neuron pairs $(n=52)$; \#1 and \#2 represent the two neurons of each neuron pair, respectively. The coactivation probability of neuron pairs is slightly higher than chance $\left(6.8\right.$ vs $5.4 \%, p=4.2 \times 10^{-9}$, paired $t$ test).

subpopulation of ACC neurons (preferentially type I). In addition, ripple events did not always precede the activation of ACC type I neurons. In fact, type I neurons showed postripple activation approximately one quarter of the time, and importantly, these neurons were selectively recruited after individual ripple events. These results are consistent with the view that the hippocampus sends specific information to selective cortical neurons for memory consolidation.

Sparse monosynaptic projections from the hippocampus to the ACC have been reported (Cenquizca and Swanson, 2007;
Rajasethupathy et al., 2015). However, the exact pathway of this hippocampus-to-ACC signal transmission remains unclear. We found that electrical stimulation of the CA1 excited ACC neurons with latencies ranging from 5 to $60 \mathrm{~ms}$ (mean latency of $23 \mathrm{~ms}$ ). Similarly, the latencies between the peak of ripple activity and the peak firing of ACC type I neurons ranged from 6 to $32 \mathrm{~ms}$ (mean latency of $12 \mathrm{~ms}$ ). These varying latencies suggest that signal transmission from the hippocampus to the ACC involves monosynaptic and multisynaptic pathways. 
A

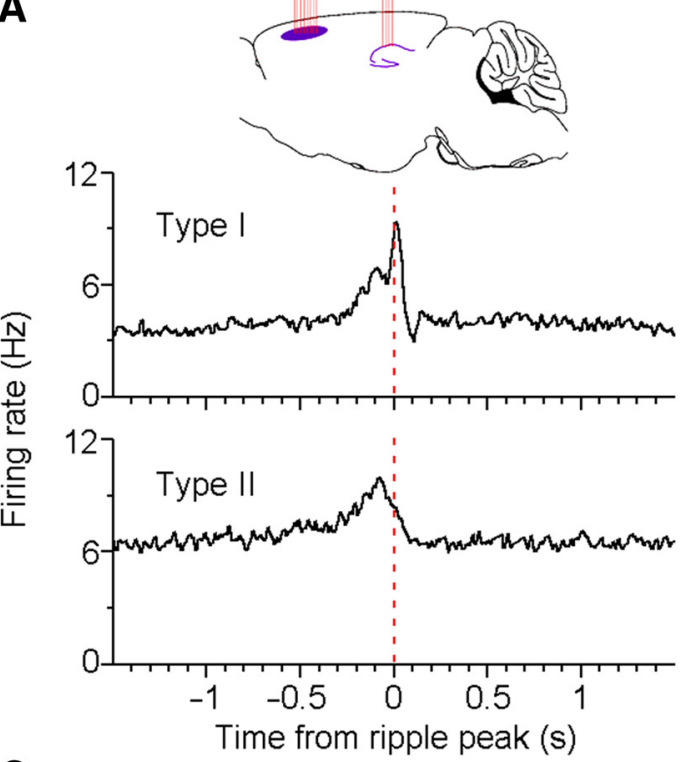

C

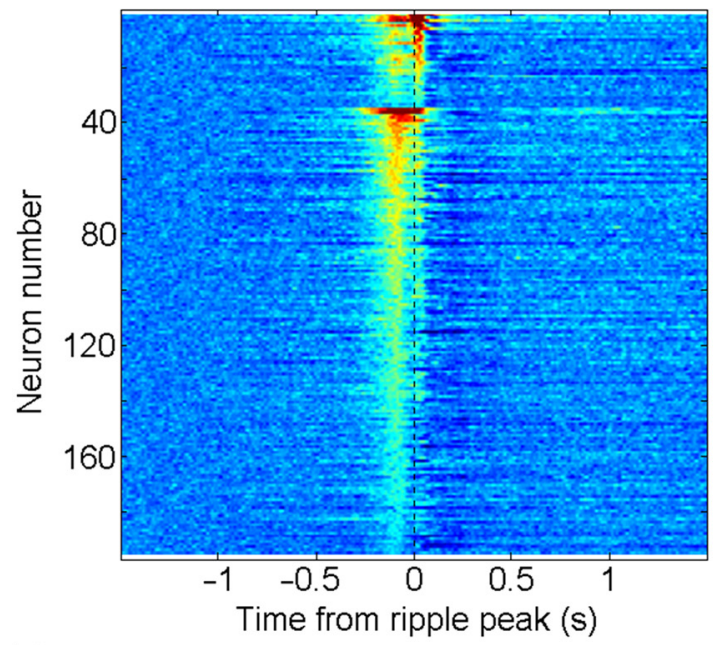

E

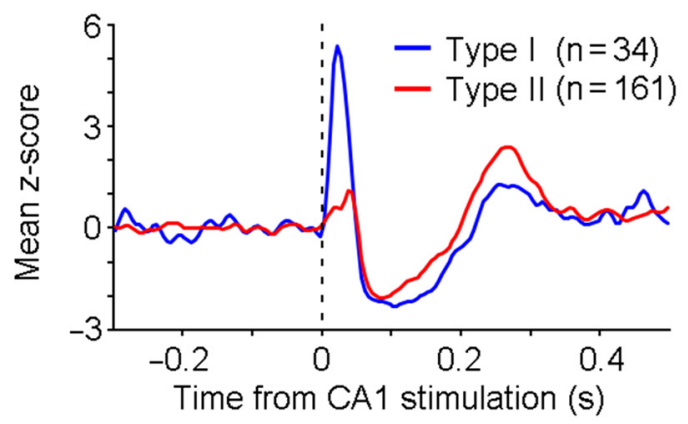

B

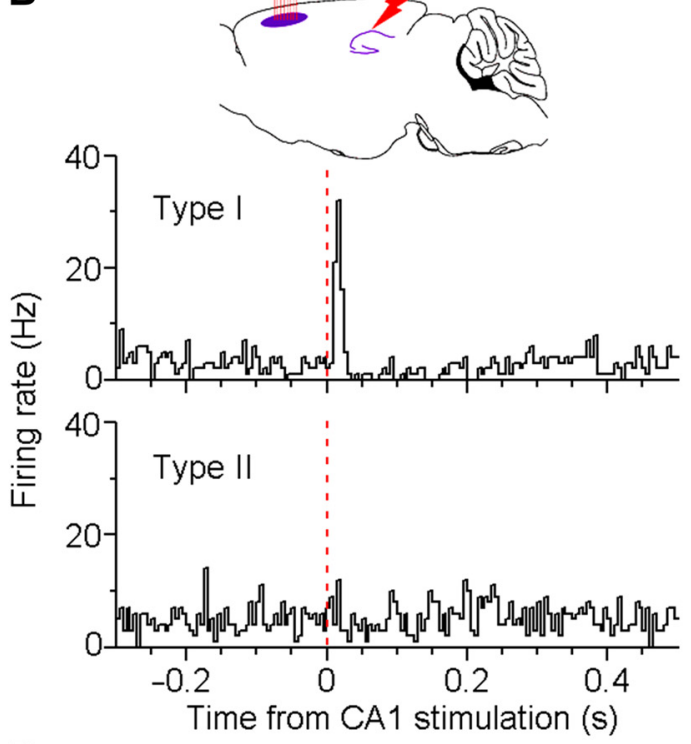

D

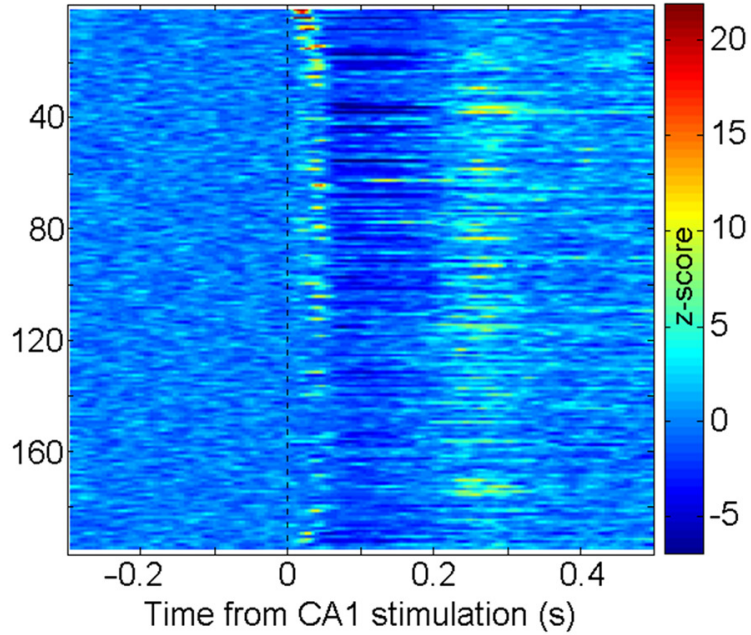

$\mathbf{F}$

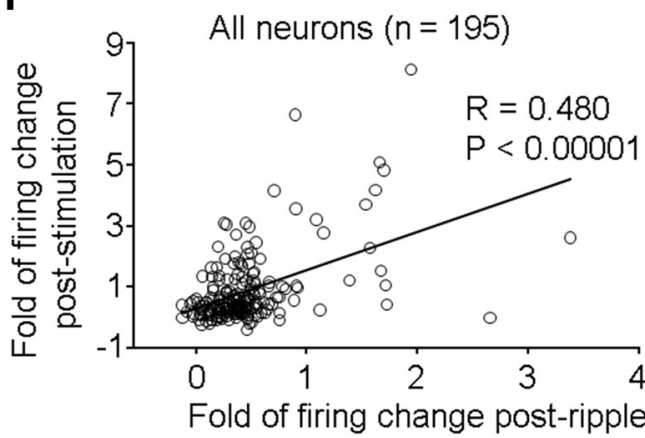

Figure 5. Hippocampal CA1 stimulation activates subpopulation of ACC neurons. $A$, Activity of two simultaneously recorded ACC neurons in relation to ripple peak ( $n=3723) . B$, Activity of the same two neurons (as shown in $A$ ) upon CA1 electrical stimulation (averaged $>200$ trials). C, Z-scored activity of 195 ACC neurons in relation to ripple peak. Neurons 1-34 and 35-195 are type I and II neurons, respectively. D, Activity of the same 195 neurons (arranged in the same order as shown in $C$ ) upon CA1 electrical stimulation. $\boldsymbol{E}$, Mean activity of type I $(n=34)$ and type II neurons ( $n=$ 161) upon CA1 electrical stimulation. Electrical stimulation: one-pulse; pulse width, $0.1 \mathrm{~ms}$; current, half of the trials $50 \mu \mathrm{A}$ and the other half $100 \mu \mathrm{A}$. $\boldsymbol{F}$, The postripple firing change of ACC neurons is positively correlated with the $\mathrm{CA} 1$ stimulation-evoked firing change of ACC neurons. Each circle represents one ACC neuron.

\section{Cortex-to-hippocampus information flow during sleep}

We found that almost all ACC neurons increased their activity just before hippocampal ripple activity during SWS. This observation is consistent with recent animal and human studies showing that cortical slow waves typically begin in the cortex and only later reach medial temporal lobe structures and the hippocampus (Isomura et al., 2006; Nir et al., 2011). Moreover, we observed that ripple activity increased during ACC up states, and decreased during the down state. This is in line with a number of studies showing that hippocampal ripple activity occurs preferentially 
A

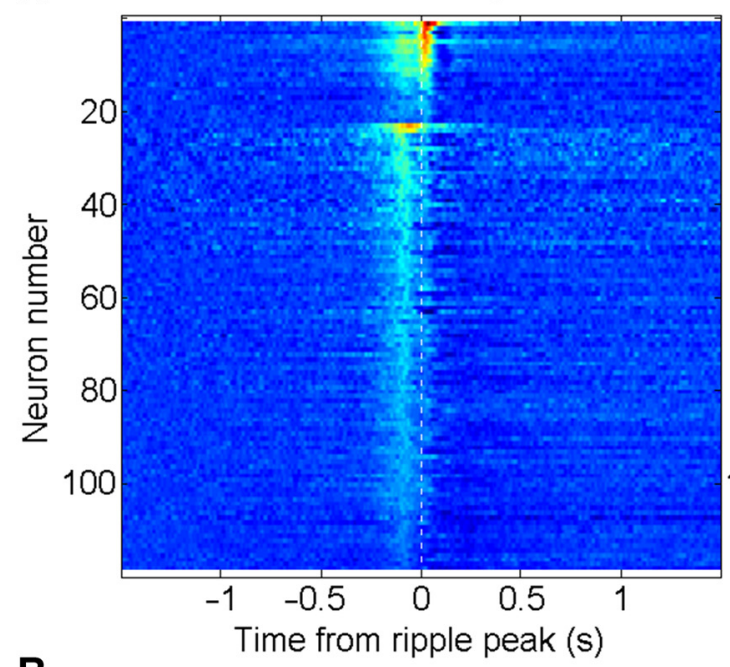

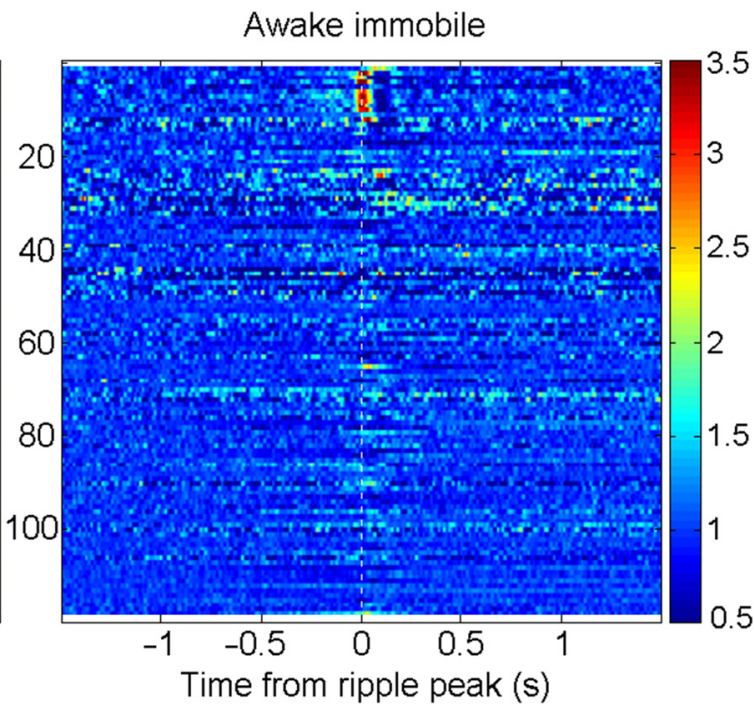

Awake immobile

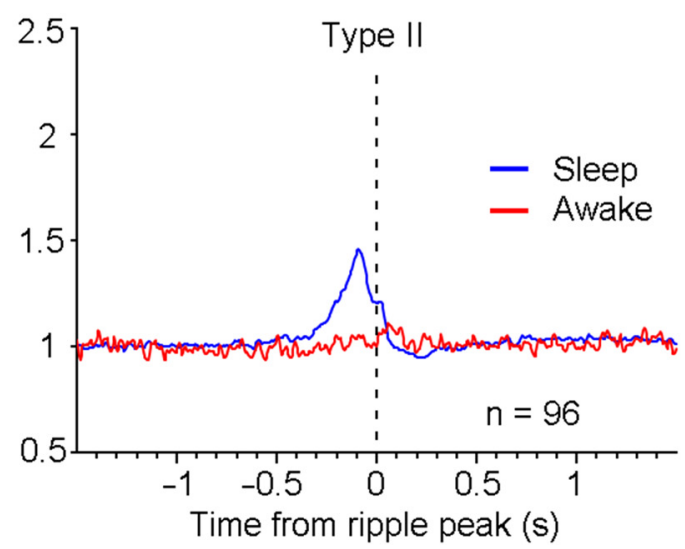

Figure 6. ACC neurons display differential ripple-associated activity between sleep and awake immobile states. $A$, Activity of 118 ACC neurons in relation to ripple peak during sleep (left) and awake immobile (right) states. Neurons in the left and right panels are arranged in the same order. Neurons 1-22 and 23-118 are type I and type II neurons, respectively. Color bar represents normalized firing frequency. $\boldsymbol{B}$, Mean normalized activity of ACC type I (left; $n=22$ ) and type II (right; $n=96$ ) neurons during sleep (blue lines) and awake immobile (red lines) states.

during the depolarized up states of cortical slow oscillation (Sirota et al., 2003; Isomura et al., 2006; Mölle et al., 2006; Nir et al., 2011; but see Battaglia et al., 2004; Hahn et al., 2007). These observations led to the hypothesis that the cortex initiates or modulates hippocampal activity to "supervise" the signal transduction and memory consolidation process (Sirota et al., 2003; Ji and Wilson, 2007). In other words, cortical activity may bias the timing or content of the ripple-associated neural firings in the CA1, as distinct populations of CA1 neurons are known to be active at individual ripple events. The specificity of information flow from the ACC to the hippocampus is supported by a recent study showing that photostimulation of the ACC-to-CA1 axonal terminals, but not the CA1 itself, is sufficient to retrieve memories of recent experiences (Rajasethupathy et al., 2015). However, the ventral (area 2) ACC, where unit activities were recorded in the present study, does not appear to project directly to the CA1 (Rajasethupathy et al., 2015). Therefore, the communication from the ventral ACC to the CA1 seems to be multisynaptic. Consistently, mean latency from the peak of ACC firing rates to the ripple peak was $86 \mathrm{~ms}$ (Fig. $4 B$ ).

There seem to be important differences in hippocampal ripples between awake and sleep states (Buzsáki, 2015). The preripple activation of ACC neurons was present during SWS; however, it was absent during the awake immobile state (Fig. 6). Consistently, previous studies found little preripple activation of cortical neurons in the awake state (Remondes and Wilson, 2015; Jadhav et al., 2016). The absence of preripple activation of ACC neurons suggests that cortical activation is not necessary for the generation of ripples. Indeed, earlier studies have shown that bilateral removal of the entorhinal cortex, the major cortical input to the hippocampus, does not affect hippocampal sharpwave ripple activity (Buzsáki et al., 1983; Suzuki and Smith, 1988; Buzsáki, 2015). In addition, ripple activity can occur in isolated hippocampal slices when cortical input is minimal or absent (Maier et al., 2003; Behrens et al., 2005).

The differences in ripple-associated activity between awake and sleep states have also been reported within the hippocampus: while sleep ripples are associated with memory reactivation (Wilson and McNaughton, 1994; Nádasdy et al., 1999; Lee and Wilson, 2002), awake ripples may support cognitive functions, such as behavioral planning, likely by influencing cortical activity (Pfeiffer and Foster, 2013; Yu and Frank, 2015). In addition, the absence of cortical inputs to the hippocampus during awake ripple episodes may protect freshly acquired information from alteration. It may be necessary to transform 
A

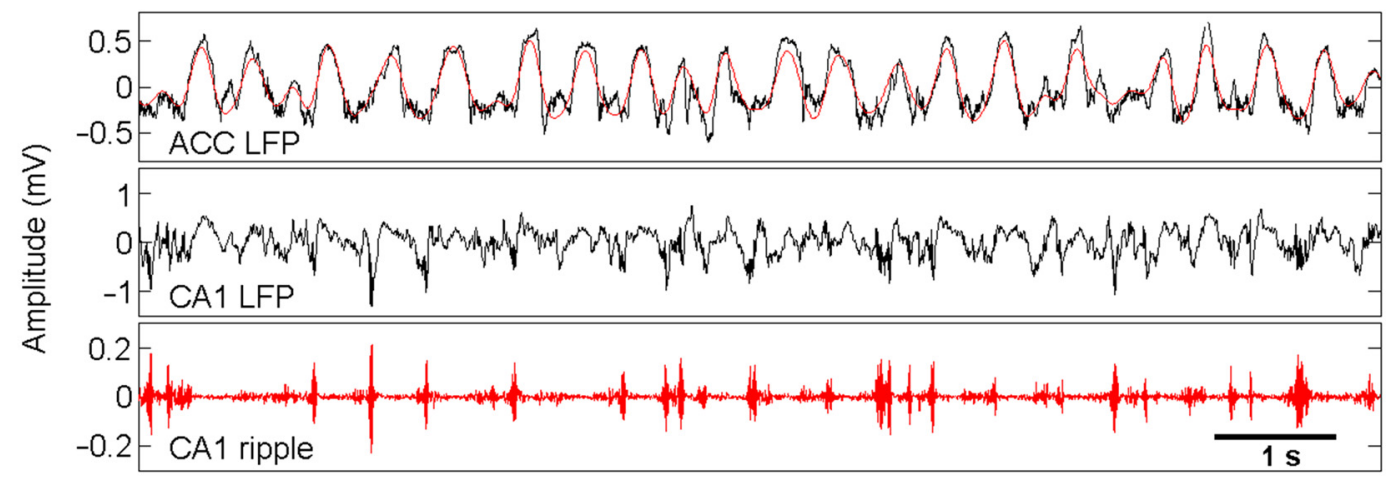

B
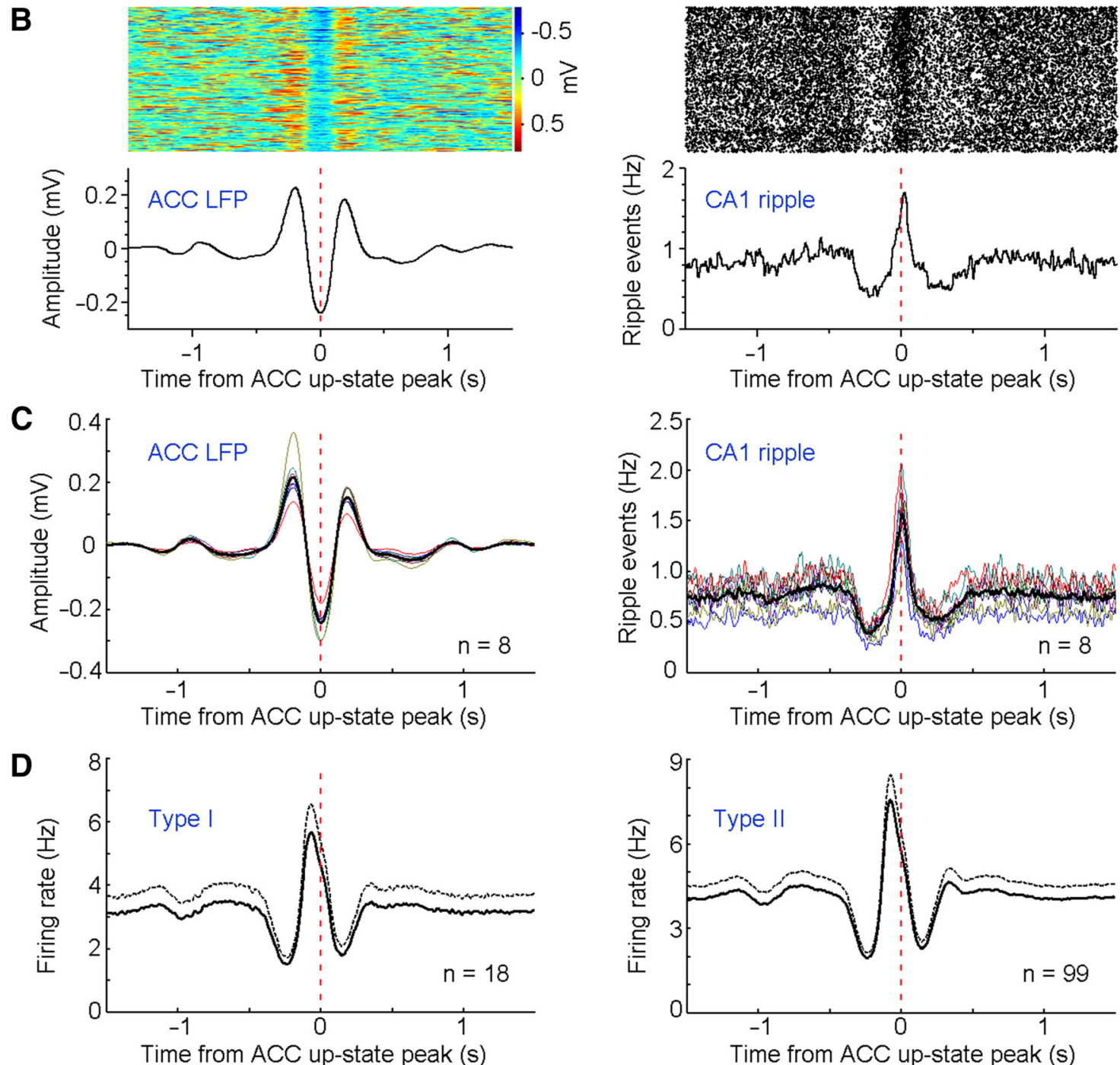

Figure 7. Hippocampal ripples preferentially occur at ACC up state. $\boldsymbol{A}$, Top, Representative ACC LFP (black line) and filtered potential between $1-4$ Hz (red line). Middle and bottom, CA1 LFP and filtered ripple activity $(150-250 \mathrm{~Hz}$ ), respectively. The LFPs of the ACC and CA1 were recorded simultaneously. $B$, Representative ACC LFP (left) and ripple events (right) in relation to the peak of ACC up states ( $n=8394$; recorded in 1 session). C, Mean (black lines) and individual (color lines; $n=8$ mice) ACC LFPs (left) and ripple event frequency (right) in relation to the peak of ACC up state. $D$, Mean (solid line) and SEM (dashed lines) of firing rates of ACC type I (left; $n=18)$ and type II (right; $n=99)$ neurons in relation to the peak of ACC up state.

the information in a more secure form before it is integrated with the information stored in the cortex. Hippocampal ripples are not only associated with the process to transduce hippocampal information to the cortex, but also to transform information temporarily stored in the dentate/CA3 to the CA1
(Buzsáki, 1989). In this light, the function of cortical preripple activation may be to help integrate newly acquired information with information previously stored. It is of great interest to determine precise role of the preripple activity in the ACC and other cortical regions. 


\section{References}

Battaglia FP, Sutherland GR, McNaughton BL (2004) Hippocampal sharp wave bursts coincide with neocortical "up-state" transitions. Learn Mem 11:697-704. CrossRef Medline

Behrens CJ, van den Boom LP, de Hoz L, Friedman A, Heinemann U (2005) Induction of sharp wave-ripple complexes in vitro and reorganization of hippocampal networks. Nat Neurosci 8:1560-1567. CrossRef Medline

Bontempi B, Laurent-Demir C, Destrade C, Jaffard R (1999) Timedependent reorganization of brain circuitry underlying long-term memory storage. Nature 400:671-675. CrossRef Medline

Buzsáki G (1989) Two-stage model of memory trace formation: a role for 'noisy' brain states. Neuroscience 31:551-570. CrossRef Medline

Buzsáki G (1998) Memory consolidation during sleep: a neurophysiological perspective. J Sleep Res 7 [Suppl 1]:17-23. Medline

Buzsáki G (2015) Hippocampal sharp wave-ripple: a cognitive biomarker for episodic memory and planning. Hippocampus 25:1073-1188. CrossRef Medline

Buzsáki G, Leung LW, Vanderwolf CH (1983) Cellular bases of hippocampal EEG in the behaving rat. Brain Res 287:139-171. Medline

Carr MF, Jadhav SP, Frank LM (2011) Hippocampal replay in the awake state: a potential substrate for memory consolidation and retrieval. Nat Neurosci 14:147-153. CrossRef Medline

Cenquizca LA, Swanson LW (2007) Spatial organization of direct hippocampal field CA1 axonal projections to the rest of the cerebral cortex. Brain Res Rev 56:1-26. CrossRef Medline

Davidson TJ, Kloosterman F, Wilson MA (2009) Hippocampal replay of extended experience. Neuron 63:497-507. CrossRef Medline

Diekelmann S, Born J (2010) The memory function of sleep. Nat Rev Neurosci 11:114-126. CrossRef Medline

Ego-Stengel V, Wilson MA (2010) Disruption of ripple-associated hippocampal activity during rest impairs spatial learning in the rat. Hippocampus 20:1-10. CrossRef Medline

Eichenbaum H (2000) A cortical-hippocampal system for declarative memory. Nat Rev Neurosci 1:41-50. CrossRef Medline

Foster DJ, Wilson MA (2006) Reverse replay of behavioural sequences in hippocampal place cells during the awake state. Nature 440:680-683. CrossRef Medline

Frankland PW, Bontempi B, Talton LE, Kaczmarek L, Silva AJ (2004) The involvement of the anterior cingulate cortex in remote contextual fear memory. Science 304:881-883. CrossRef Medline

Franklin KBJ, Paxinos G (2007) The mouse brain in stereotaxic coordinates, 3rd edition. New York: Elsevier.

Girardeau G, Zugaro M (2011) Hippocampal ripples and memory consolidation. Curr Opin Neurobiol 21:452-459. CrossRef Medline

Girardeau G, Benchenane K, Wiener SI, Buzsáki G, Zugaro MB (2009) Selective suppression of hippocampal ripples impairs spatial memory. Nat Neurosci 12:1222-1223. CrossRef Medline

Goshen I, Brodsky M, Prakash R, Wallace J, Gradinaru V, Ramakrishnan C, Deisseroth K (2011) Dynamics of retrieval strategies for remote memories. Cell 147:678-689. CrossRef Medline

Hahn TT, Sakmann B, Mehta MR (2007) Differential responses of hippocampal subfields to cortical up-down states. Proc Natl Acad Sci U S A 104:5169-5174. CrossRef Medline

Isomura Y, Sirota A, Ozen S, Montgomery S, Mizuseki K, Henze DA, Buzsáki G (2006) Integration and segregation of activity in entorhinal-hippocampal subregions by neocortical slow oscillations. Neuron 52:871-882. CrossRef Medline

Jadhav SP, Kemere C, German PW, Frank LM (2012) Awake hippocampal sharp-wave ripples support spatial memory. Science 336:1454-1458. CrossRef Medline

Jadhav SP, Rothschild G, Roumis DK, Frank LM (2016) Coordinated excitation and inhibition of prefrontal ensembles during awake hippocampal sharp-wave ripple events. Neuron 90:113-127. CrossRef Medline

Ji D, Wilson MA (2007) Coordinated memory replay in the visual cortex and hippocampus during sleep. Nat Neurosci 10:100-107. CrossRef Medline

Lee AK, Wilson MA (2002) Memory of sequential experience in the hippocampus during slow wave sleep. Neuron 36:1183-1194. CrossRef Medline

Maier N, Nimmrich V, Draguhn A (2003) Cellular and network mechanisms underlying spontaneous sharp wave-ripple complexes in mouse hippocampal slices. J Physiol 550:873-887. CrossRef Medline

Maingret N, Girardeau G, Todorova R, Goutierre M, Zugaro M (2016) Hippocampo-cortical coupling mediates memory consolidation during sleep. Nat Neurosci 19:959-964. CrossRef Medline
Maviel T, Durkin TP, Menzaghi F, Bontempi B (2004) Sites of neocortical reorganization critical for remote spatial memory. Science 305:96-99. CrossRef Medline

McClelland JL, McNaughton BL, O'Reilly RC (1995) Why there are complementary learning-systems in the hippocampus and neocortex-insights from the successes and failures of connectionist models of learning and memory. Psychol Rev 102:419-457. Medline

Mölle M, Born J (2009) Hippocampus whispering in deep sleep to prefrontal cortex-for good memories? Neuron 61:496-498. CrossRef Medline

Mölle M, Yeshenko O, Marshall L, Sara SJ, Born J (2006) Hippocampal sharp wave-ripples linked to slow oscillations in rat slow-wave sleep. J Neurophysiol 96:62-70. CrossRef Medline

Nádasdy Z, Hirase H, Czurkó A, Csicsvari J, Buzsáki G (1999) Replay and time compression of recurring spike sequences in the hippocampus. J Neurosci 19:9497-9507. Medline

Nir Y, Staba RJ, Andrillon T, Vyazovskiy VV, Cirelli C, Fried I, Tononi G (2011) Regional slow waves and spindles in human sleep. Neuron 70: 153-169. CrossRef Medline

Peyrache A, Khamassi M, Benchenane K, Wiener SI, Battaglia FP (2009) Replay of rule-learning related neural patterns in the prefrontal cortex during sleep. Nat Neurosci 12:919-926. CrossRef Medline

Pfeiffer BE, Foster DJ (2013) Hippocampal place-cell sequences depict future paths to remembered goals. Nature 497:74-79. CrossRef Medline

Rajasethupathy P, Sankaran S, Marshel JH, Kim CK, Ferenczi E, Lee SY, Berndt A, Ramakrishnan C, Jaffe A, Lo M, Liston C, Deisseroth K (2015) Projections from neocortex mediate top-down control of memory retrieval. Nature 526:653-659. CrossRef Medline

Remondes M, Wilson MA (2015) Slow-gamma rhythms coordinate cingulate cortical responses to hippocampal sharp-wave ripples during wakefulness. Cell Rep 13:1327-1335. CrossRef Medline

Restivo L, Vetere G, Bontempi B, Ammassari-Teule M (2009) The formation of recent and remote memory is associated with time-dependent formation of dendritic spines in the hippocampus and anterior cingulate cortex. J Neurosci 29:8206-8214. CrossRef Medline

Siapas AG, Wilson MA (1998) Coordinated interactions between hippocampal ripples and cortical spindles during slow-wave sleep. Neuron 21:1123-1128. CrossRef Medline

Sirota A, Csicsvari J, Buhl D, Buzsáki G (2003) Communication between neocortex and hippocampus during sleep in rodents. Proc Natl Acad Sci U S A 100:2065-2069. CrossRef Medline

Skaggs WE, McNaughton BL (1996) Replay of neuronal firing sequences in rat hippocampus during sleep following spatial experience. Science 271: 1870-1873. CrossRef Medline

Squire LR (1992) Memory and the hippocampus—a synthesis from findings with rats, monkeys, and humans. Psychol Rev 99:195-231. CrossRef Medline

Suzuki SS, Smith GK (1988) Spontaneous EEG spikes in the normal hippocampus. IV. Effects of medial septum and entorhinal cortex lesions. Electroencephalogr Clin Neurophysiol 70:73-83. CrossRef Medline

Tononi G, Massimini M, Riedner BA (2006) Sleepy dialogues between cortex and hippocampus: Who talks to whom? Neuron 52:748-749. CrossRef Medline

Wang DV, Yau HJ, Broker CJ, Tsou JH, Bonci A, Ikemoto S (2015) Mesopontine median raphe regulates hippocampal ripple oscillation and memory consolidation. Nat Neurosci 18:728-735. CrossRef Medline

Wang SH, Morris RG (2010) Hippocampal-neocortical interactions in memory formation, consolidation, and reconsolidation. Annu Rev Psychol 61:49-79, C1-C4. CrossRef Medline

Weible AP, Rowland DC, Monaghan CK, Wolfgang NT, Kentros CG (2012) Neural correlates of long-term object memory in the mouse anterior cingulate cortex. J Neurosci 32:5598-5608. CrossRef Medline

Wierzynski CM, Lubenov EV, Gu M, Siapas AG (2009) State-dependent spike-timing relationships between hippocampal and prefrontal circuits during sleep. Neuron 61:587-596. CrossRef Medline

Wilson MA, McNaughton BL (1994) Reactivation of hippocampal ensemble memories during sleep. Science 265:676-679. CrossRef Medline

Ylinen A, Bragin A, Nádasdy Z, Jandó G, Szabó I, Sik A, Buzsáki G (1995) Sharp wave-associated high-frequency oscillation $(200 \mathrm{~Hz})$ in the intact hippocampus: network and intracellular mechanisms. J Neurosci 15:3046. Medline

Yu JY, Frank LM (2015) Hippocampal-cortical interaction in decision making. Neurobiol Learn Memory 117:34-41. CrossRef Medline 